HNO $2021 \cdot 69: 74$

https://doi.org/10.1007/s00106-020-00972-4

Angenommen: 25. November 2020

Online publiziert: 21. Dezember 2020

(c) Springer Medizin Verlag $\mathrm{GmbH}$, ein Teil von Springer Nature 2020

H. L. Sieron - J. Lindemann

Klinik für Hals-, Nasen- und Ohrenheilkunde, Universitätsklinikum Ulm, Ulm, Deutschland

\section{Zur Funktion und Physiologie der Kieferhöhle}

\section{Erwiderung}

Zum Leserbrief von Behrbohm H (2020) Welche Funktion haben die Nasennebenhöhlen? HNO 68. https://doi.org/10.1007/s00106-02000971-5

\section{Originalbeitrag}

Sieron HL et al. (2020) Funktion und Physiologie der Kieferhöhle. HNO 68:566-572. https:// doi.org/10.1007/s00106-020-00869-2

Sehr geehrter Herr Prof. Behrbohm,

vielen Dank für den interessanten Kommentar.

Mit freundlichen Grüßen

Dr. med. H. Sieron

Prof. Dr. med. J. Lindemann

\section{Korrespondenzadresse}

\section{Dr. med. H. L. Sieron}

Klinik für Hals-, Nasen- und Ohrenheilkunde, Universitätsklinikum UIm

Frauensteige 12, $89075 \mathrm{Ulm}$, Deutschland

hannah.sieron@uniklinik-ulm.de

Interessenkonflikt. H.L. Sieron und J. Lindemann geben an, dass kein Interessenkonflikt besteht. 